\title{
Statistical Optimization of Saccharification Process Using Amorphophallus Paeoniifolius Tubers into Fermentable Sugars for Bioethanol Production in Stirred Tank Batch Reactor (STBR)
}

\section{S.P. Rakshitha}

Department of Biotechnology Engineering, N.M.A.M. Institute of Technology (Visvesvaraya Technological University, Belagavi),

\section{K. V. Keerthana}

Department of Biotechnology Engineering, N.M.A.M. Institute of Technology (Visvesvaraya Technological University, Belagavi),

\section{P. Anjuna}

Department of Biotechnology Engineering, N.M.A.M. Institute of Technology (Visvesvaraya Technological University, Belagavi),

\section{S.G. Sangam}

Department of Biotechnology Engineering, N.M.A.M. Institute of Technology (Visvesvaraya Technological University, Belagavi),

\section{K. Sandesh}

Department of Biotechnology Engineering, N.M.A.M. Institute of Technology (Visvesvaraya Technological University, Belagavi),

\section{Vinayaka B. Shet}

Department of Biotechnology Engineering, N.M.A.M. Institute of Technology (Visvesvaraya Technological University, Belagavi),

\section{J. N. Neetha}

Department of Biotechnology Engineering, N.M.A.M. Institute of Technology (Visvesvaraya Technological University, Belagavi),

\section{P. Ujwal}

Department of Biotechnology Engineering, N.M.A.M. Institute of Technology (Visvesvaraya Technological University, Belagavi),

N.M. Mubarak ( $\nabla$ mubarak.mujawar@curtin.edu.my )

Curtin University Sarawak 
Keywords: Amorphophallus paeoniifolius, Central Composite Design (CCD), stirred tank batch reactor (STBR), Bioethanol.

Posted Date: December 11th, 2020

DOI: https://doi.org/10.21203/rs.3.rs-120742/v1

License: (c) (i) This work is licensed under a Creative Commons Attribution 4.0 International License. Read Full License 


\title{
Statistical Optimization of Saccharification Process using Amorphophallus paeoniifolius Tubers into Fermentable Sugars for Bioethanol Production in Stirred Tank Batch Reactor (STBR)
}

\author{
S.P. Rakshitha ${ }^{1}$, K. V. Keerthana ${ }^{1}$, P. Anjuna ${ }^{1}$, S.G. Sangam ${ }^{1}$, K. Sandesh ${ }^{1}$, Vinayaka B. Shet ${ }^{1}$, \\ J. N. Neetha ${ }^{1}$, P. Ujwal ${ }^{1 *}$, N. M. Mubarak ${ }^{2 *}$ \\ ${ }^{1}$ Department of Biotechnology Engineering, N.M.A.M. Institute of Technology (Visvesvaraya \\ Technological University, Belagavi), Nitte-574110, Udupi District, Karnataka, India. \\ ${ }^{2}$ Department of Chemical Engineering, Faculty of Engineering and Science, Curtin University, \\ 98009 Miri, Sarawak Malaysia
}

E-mail addresses: mubarak.mujawar@ curtin.edu.my ; mubarak.yaseen@gmail.com (N.M. Mubarak), ujwal.p@nitte.edu.in, ujwal.p@gmail.com (Ujwal P).

\begin{abstract}
Current technologies for the production of biofuels from various renewable feedstocks have considerably captured vast scientific attention due to the fact that they can be used as an alternative fuels. Bioethanol being one of the most interesting biofuels and due to its positive impact on the environment has been categorised significantly in terms of scientific and technological investments. The aim of this study was to investigate, tubers of Amorphophallus paeoniifolius biomass as a feedstock for bioethanol production. The composition analysis of A.paeoniifolius tubers revealed high carbohydrate content $(78.30 \pm 0.33 \%)$. The feedstock was subjected to physicochemical pretreatment by treating with dilute acid followed by pressure cooking. The pretreatment factors were optimized by CCD using RSM approach. The optimum condition was found to be $1.32 \% \mathrm{v} / \mathrm{v}$ of $\mathrm{HCl}, 5.83 \% \mathrm{w} / \mathrm{v}$ of Elephant Foot Yam Biomass and $66.84 \mathrm{~min}$ of pressure cooking time yielding $45.87 \mathrm{~g} / \mathrm{L}$ of total sugar. The second order polynomial equation was generated for the saccharification of the biomass and validated with $\mathrm{R}^{2}$ 0.89. The fermentation of pretreated biomass in the presence of Saccharomyces cerevisiae MTCC170 yielded $22.12 \pm 0.62 \mathrm{~g} / \mathrm{L}$ of bioethanol at $120 \mathrm{~h}$ utilising $92 \%$ of initial total sugar.
\end{abstract}


The resultant ethanol yield and productivity was estimated to be $0.51 \mathrm{~g} / \mathrm{g}$ and $0.30 \mathrm{~g} / \mathrm{L} . \mathrm{h}$ respectively. The Gompertz model equation was applied to experimental data using nonlinear regression with the least square method and the kinetic fermentation parameters such as maximum ethanol concentration $\left(\mathrm{P}_{\mathrm{m}}\right)$, production rate $\left(\mathrm{r}_{\mathrm{pm}}\right)$ and lag phase $(\mathrm{h})$ were estimated to be $P_{m}=21.90 \mathrm{~g} / \mathrm{L}, \mathrm{r}_{\mathrm{pm}}=0.57 \mathrm{~g} / \mathrm{L} \cdot \mathrm{h}$ and $\mathrm{t}_{\mathrm{L}}=8.22 \mathrm{~h}$.

Key words: Amorphophallus paeoniifolius, Central Composite Design (CCD), stirred tank batch reactor (STBR), Bioethanol.

\section{Introduction}

Rise in global warming in recent years has promoted the research to focus on various aspects of alternative renewable fuel sources. This has attracted the production and utilization of various bioresources for their progressive application thus making an attempt in reducing the fossil fuel consumption significantly. ${ }^{1}$ Although substantial research has been collaborated in the resultant production of bioethanol, there is still a need for steady implementation of processes and optimization techniques ${ }^{2}$. It is reviewed that the present biofuel demand is expected to rise between 250 - 500 billion litres per year till $2045^{3}$. To meet this exorbitant demand there is a necessity to quantify a number of unexplored feedstock in order to meet the concerned capacity production with its advancement. As per the availability of reports some of the successfully explored potential starchy sources like wheat ${ }^{4,5}$, corn ${ }^{6,7}$, barley ${ }^{8,9}$, sweet potato ${ }^{10}$, maize ${ }^{11}$, rice ${ }^{12}$, potato ${ }^{13}$, cassava ${ }^{14}$ and waste food grains ${ }^{15}$ already has gained importance with defined technology and resources. Though these food crops have a huge demand in agriculture, there are all possibilities that they may pose threats of food vs. fuel conflicts ${ }^{16}$. But surplus growth of selected starchy sources can always be grown in field to compensate this status. It is estimated that 2.7 billion tons of these crops are harvested annually and are available for use ${ }^{17}$. The total annual production of starchy feedstock depends on the 
fertile soil, available land and productivity. In United State $35 \%$ of the harvested maize grain is utilized for bioethanol production which yields 53 million litres of bioethanol annually ${ }^{18}$. Cassava starch grown in subtropical countries is another starchy residues used for bioethanol production and is compatible with current corn to ethanol technology ${ }^{19}$. Sorghum is grown in dry region and can become a good substitute for ethanol production ${ }^{20}$.

Production of bioethanol is governed by various process parameters such as degree of hydrolysis, inoculum size, broth $\mathrm{pH}$ and fermentation time ${ }^{21}$. Yeast plays a critical role in fermenting wide range of hexose and pentose sugars into bioethanol, thus enhancing the quantity and rate of bioethanol production ${ }^{22}$. Optimization of pre-treatment process parameters is a critical step in the production of an effective and economic process. In the last decades various research have been focusing on identification and demonstration of pretreatment techniques for bioethanol production ${ }^{23-25}$. However, nature of feedstock decides the type of pretreatment and economy of process. To reduce the cost of overall process, the factors affecting the pretreatment steps need to be identified at an optimum condition ${ }^{26}$. An optimization technique adapts systematic statistical approach to standardize the maximum output based on the input given to the process. It is also carried out to achieve maximum or minimum response, depending on the process parameters ${ }^{27}$.

Amorphophallus paeoniifolius tuber (Elephant Foot Yam) is a plant belonging to the family of aroids, Araceae. It is grown abundantly in the tropical areas of the world for its edible tubers. These tubers possess high starchy content amounting almost $85 \%$ of the total dry weight ${ }^{28-30}$. The present research aims to focus on an unexplored source of Elephant Foot Yam Biomass (EFYB) and pretreatment optimisation for bioethanol production. The optimization of saccharification process was carried out using CCD and the experimental response was fitted to the second order mathematical model. The hydrolysate obtained after the optimum pretreatment process was subjected to fermentation in the presence of yeast Sacchromyces 
cerevisiae MTCC 170. Furthermore, fermentation studies were carried out in laboratory stirred tank batch reactor (STBR) and the rate of ethanol formation and substrate utilisation was determined. The kinetic parameters of bioethanol fermentation were fit into the experimental data using non-linear regression with least square method.

\section{Results and Discussion}

\subsection{Physicochemical pretreatment of EFYB}

The compositional analysis of EFYB reveals $11.56 \pm 0.30 \%$ protein, $6.7 \pm 0.12 \%$ moisture, $3.44 \pm 0.027 \%$ ash content and the carbohydrate to be $78.30 \pm 0.33 \%$. This rich carbohydrate content in EFYB proves to be a potential source for bioethanol production. The rich concentration of carbohydrates in biomass eases the hydrolysis process and thus increases the sugar yield per weight of biomass, thus increasing the overall bioethanol yield and productivity. The parameter values obtained in this study were in good agreement to the reports by Behera et al ${ }^{30}$ and Suriya et al ${ }^{29}$. The marginal change in the composition could be attributed to geographical location, analysis method and accuracy.

The pretreatment of EFYB was processed by treating with dilute $\mathrm{HCl}$ followed by pressure cooking. The effect of acid concentration, EFYB load and pressure cooking time on total sugar is presented in Figure 1. From the figure it is clearly evident that the change in pretreatment parameter greatly affects the hydrolysis rate. Increase in EFYB load indicates a positive effect on total sugar release till $6 \% \mathrm{w} / \mathrm{v}$ releasing $71.38 \pm 0.29 \mathrm{~g} / \mathrm{L}$ of sugar (Figure 1a). Further increase in biomass load beyond $6 \% \mathrm{w} / \mathrm{v}$ stabilizes the hydrolysis process. This could be due to an increase in biomass load increasing the surface area which further leads to poor wettability of biomass surface. The hydrolysis process increases at a steeper rate by increasing the time of pressure cooking of acid treated biomass. The pressure point inside the pressure cooker was attained at $15 \mathrm{~min}$ of heating. The maximum sugar release $(70.83 \pm 0.45 \mathrm{~g} / \mathrm{L})$ was observed at 
40min of pressure cooking (Figure 1b). However, extending the pressure cooking time resulted in a significant loss of total sugar $(57.95 \pm 4.5 \mathrm{~g} / \mathrm{L})$ which could be due to evaporation loss and degradation of released sugar to form inhibitory compounds ${ }^{31-33}$. It was also observed that higher residence time of pressure cooking yielded reduced volume of hydrolysate which makes the process unfavourable for fermentation. Thus, the present study indicates that high temperature $\left(121^{\circ} \mathrm{C}\right)$ and lower residence time had an impact to the method and thus was more favourable for hydrolysis.
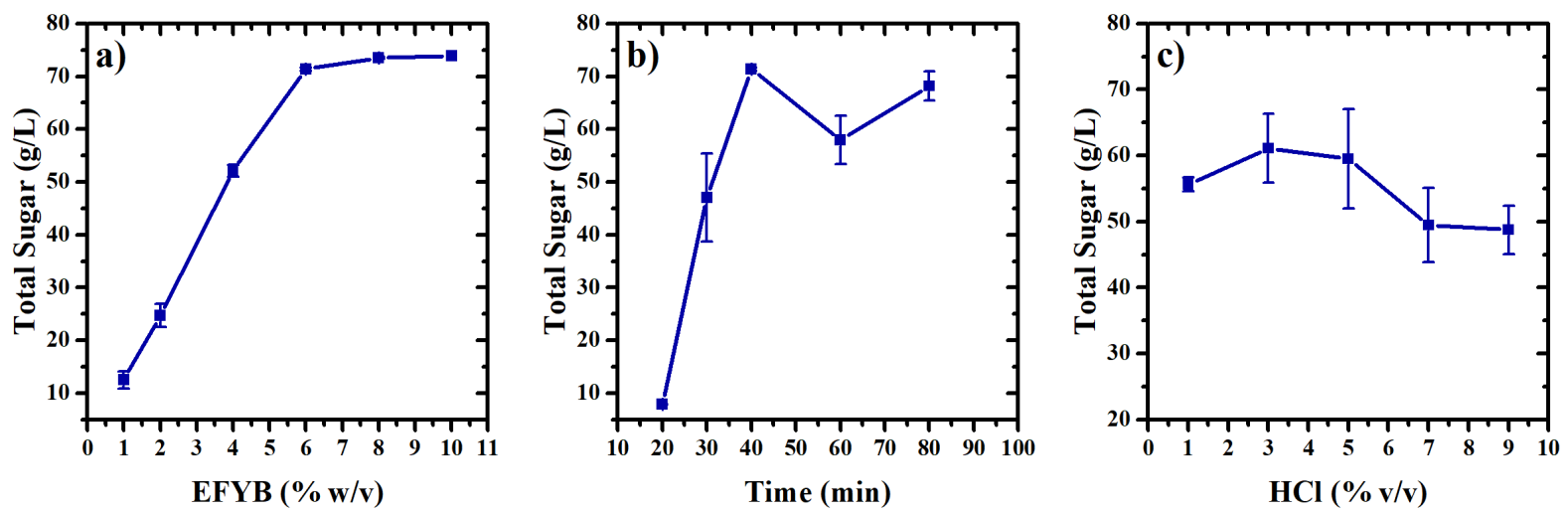

Figure 1. Effect of pretreatment parameter on fermentable sugar (a) \%EFYB (b) Pressure cooking time (c) $\% \mathrm{HCl}$ on total sugar release $(\mathrm{g} / \mathrm{L})$

The effect of dilute $\mathrm{HCl}$ on total sugar release was studied by varying the acid concentration from $1 \% \mathrm{v} / \mathrm{v}$ to $9 \% \mathrm{v} / \mathrm{v}$ (Figure 1c). Increase in acid concentration to $3 \% \mathrm{v} / \mathrm{v}$ effectively released the total sugars $(61.11 \pm 5.2 \mathrm{~g} / \mathrm{L})$. However, sugar loss steadily increased by further increasing the acid concentration above $5 \% \mathrm{v} / \mathrm{v}$, which further resulted in a decrease in total sugar release. This conversion of carbohydrate to sugar was effective in dilute acid concentration as well utilizing lesser time of hydrolysis.

\subsection{Optimization of physicochemical pretreatment condition}

The experiments were performed as per the factor combination shown in Table 2 and response was measured. The statistical significance of experimental data was performed by analysis of variable (ANOVA) and regression analysis and is presented in Table 1. Using response surface 
method the release of total sugar was analysed with second order polynomial equation. ANOVA results describes that pressure cooking time and quadratic terms of EFYB load and pressure cooking time had a p-value less than 0.05 , indicating the appropriate significant effect on total sugar release. The interaction among the pretreatment factors having $\mathrm{p}>0.05$ did not have any significant effect on response. From the Fisher's F-test, the model F-values reported in this study was observed to be 9.53. This higher F-value than the lack of fit F-value (3.90) indicates that the model was best fit. The insignificant $p$-value $(p=0.081)$ also supports the fitness of the derived model. The high coefficient of determination value for total sugar $\left(\mathrm{R}^{2}=0.896\right)$ also support the significance of the model generated.

The regression equation in coded form was deduced to represent the release of total sugar as given in Equation 1.

Total Suagr (g/L) = $\square 33.9 \square \square 5.41 \mathrm{~A} \square 11.01 \mathrm{~B} \square \square 1.081 \mathrm{C} \square \square 0.41 \mathrm{~A}^{2} \square 0.588 \mathrm{~B}^{2}$

$$
\square 0.00804 \mathrm{C}^{2} \square \square 1.418 \mathrm{AB} \square \square 0.0067 \mathrm{BC} \square 0.0033 \mathrm{BC}
$$

Equation 1

Table 1. ANOVA results for the optimization of total sugar $(\mathrm{g} / \mathrm{L})$

\begin{tabular}{|c|r|r|r|r|c|l|}
\hline Source & DF & \multicolumn{1}{c|}{ Adj SS } & Adj MS & F-Value & P-Value* & \\
\hline Model & 9 & 1343.13 & 149.24 & 9.53 & 0.001 & Significant \\
\hline Linear & 3 & 1057.15 & 352.38 & 22.50 & 0.000 & \\
\hline A & 1 & 11.27 & 11.27 & 0.72 & 0.416 & \\
\hline B & 1 & 1.54 & 1.54 & 0.10 & 0.761 & \\
\hline C & 1 & 1044.35 & 1044.35 & 66.69 & 0.000 & \\
\hline Square & 3 & 221.34 & 73.78 & 4.71 & 0.027 & \\
\hline $\mathrm{A}^{2}$ & 1 & 2.41 & 2.41 & 0.15 & 0.703 & \\
\hline $\mathrm{B}^{2}$ & 1 & 79.61 & 79.61 & 5.08 & 0.048 & \\
\hline $\mathrm{C}^{2}$ & 1 & 149.10 & 149.10 & 9.52 & 0.012 & \\
\hline 2-Way Interaction & 3 & 64.64 & 21.55 & 1.38 & 0.306 & \\
\hline A x B & 1 & 64.35 & 64.35 & 4.11 & 0.070 & \\
\hline A x C & 1 & 0.14 & 0.14 & 0.01 & 0.926 & \\
\hline B x C & 1 & 0.14 & 0.14 & 0.01 & 0.927 & \\
\hline Error & 10 & 156.59 & 15.66 & & & \\
\hline Lack-of-Fit & 5 & 124.61 & 24.92 & 3.90 & 0.081 & Insignificant \\
\hline Pure Error & 5 & 31.98 & 6.40 & & & \\
\hline
\end{tabular}




\begin{tabular}{|l|l|l|l|l|l|l|}
\hline Total & 19 & 1499.73 & & & & \\
\hline
\end{tabular}

$* \mathrm{P} \leq 0.05$ is significant

3-D interaction plot for total sugar release is presented in Figure 2. The interaction plot for the physicochemical pretreatment was studied at constant hold values of 3\%v/v HCl, $6 \% \mathrm{w} / \mathrm{v}$ EFYB and 40min of pressure cooking time. From Figure 2(a) it can be described that lower and higher value of $\mathrm{HCl}$ and EFYB load had a negative effect on total sugar release. But the acid concentration had no significant effect on rate of hydrolysis at lower pressure cooking time and sugar released increased as time of pressure cooking was raised to a higher level (Figure 2b). These observations depict that at lower temperature and pressure acid cannot penetrate deep into the cell wall and thus hydrolysis of carbohydrate seems to be ineffective. Similar trend was observed for increase in EFYB load and time. An increase in residence time of biomass inside the cooker enhances the sugar release but at higher residence time sugars gets degraded into phenolic compounds. This can be observed in Figure 2(c), wherein total sugar concentration was found to be reduced at higher residence time.

Thus observed from the surface plot presented in Figure 2 it being symmetric and optimum at the centre and within the range of level explored. Curved lines in the plot (Figure 2) proves the interactions among the factors with $\mathrm{p}<0.05$. 

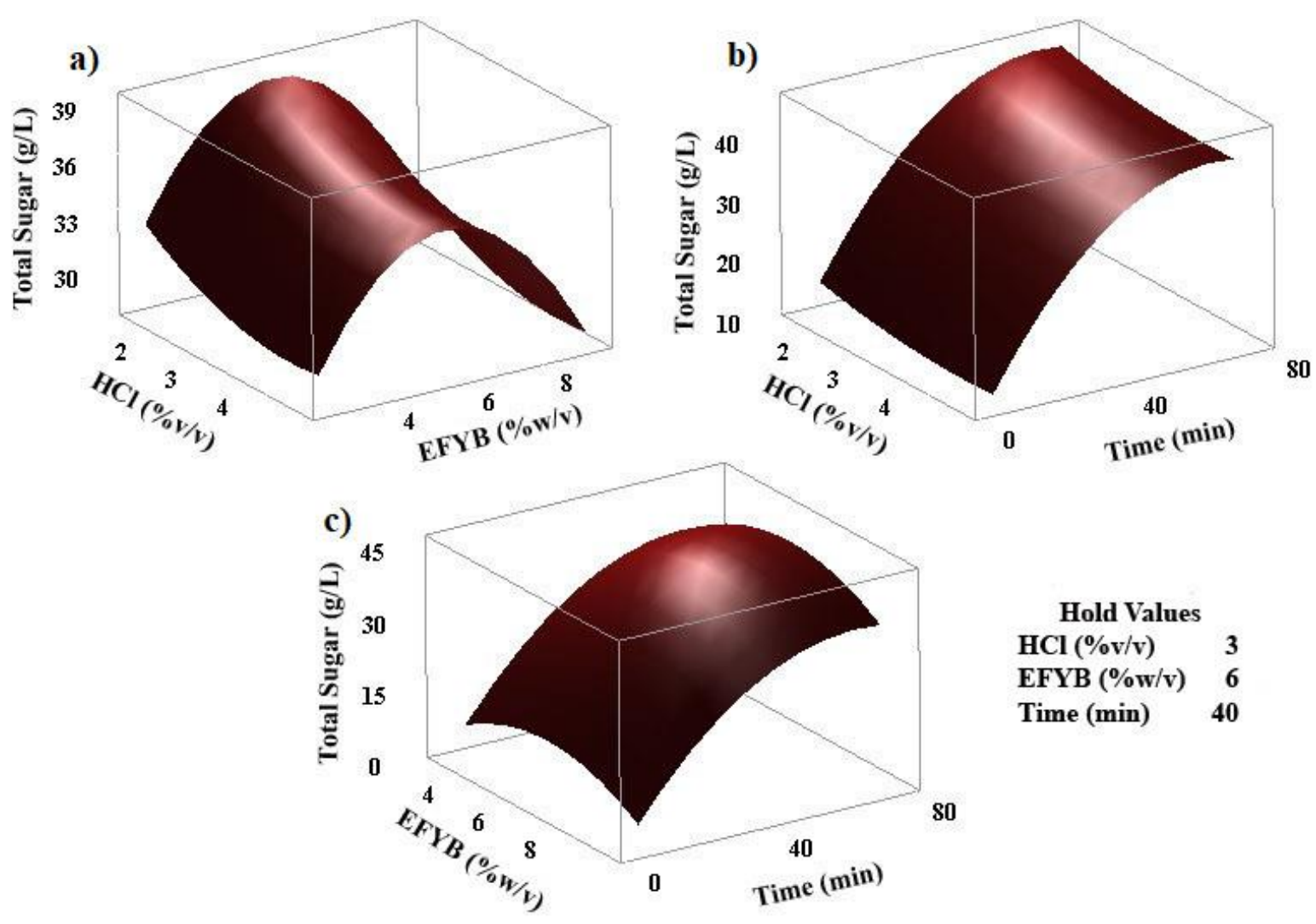

Figure 2 (a-c). 3-D surface plot for the pretreatment of EFYB for bioethanol production.

The reduced regression model was generated to get optimum conditions for pretreatment from response optimizer tool. The optimized condition for total sugar release was $1.32 \% \mathrm{v} / \mathrm{v}$ of $\mathrm{HCl}, 5.83 \% \mathrm{w} / \mathrm{v}$ of EFYB and $66.84 \mathrm{~min}$ of pressure cooking time. The generated model was validated by conducting experiment at optimal condition and comparing the experimental value with model predicted value. At optimum pretreatment condition the total sugar $45.87 \mathrm{~g} / \mathrm{L}$ was well correlated with the predicted value of total sugar $43.48 \mathrm{~g} / \mathrm{L}$ being a good fit model.

\subsection{Ethanol fermentation in lab scale stirred tank batch reactor (STBR)}

The direct fermentation of EFYB hydrolysate in STBR was carried out for different fermentation time intervals. The concentration of bioethanol and substrate utilization with respect to fermentation time is shown in Figure 3. The EFYB hydrolysate with initial sugar concentration $46.87 \mathrm{~g} / \mathrm{L}$ was taken as substrate for bioethanol fermentation in the presence of S.cerevisiae. The media was fed with $5 \% \mathrm{v} / \mathrm{v}$ of S.cerevisiae and fermentation was carried out 
at $37^{0} \mathrm{C}$. The sugar concentration reduced to $3.92 \mathrm{~g} / \mathrm{L}$ at the end of fermentation, which amounts to $92 \%$ total sugar utilization in $120 \mathrm{~h}$. The bioethanol concentration at $120 \mathrm{~h}$ of fermentation was found to be $22.12 \pm 0.62 \mathrm{~g} / \mathrm{L}$. The yield and productivity of ethanol calculated at the end of $120 \mathrm{~h}$ fermentation was found to be $0.51 \mathrm{~g}$ of ethanol/ $\mathrm{g}$ of substrate and $0.30 \mathrm{~g} / \mathrm{L}$. h respectively.

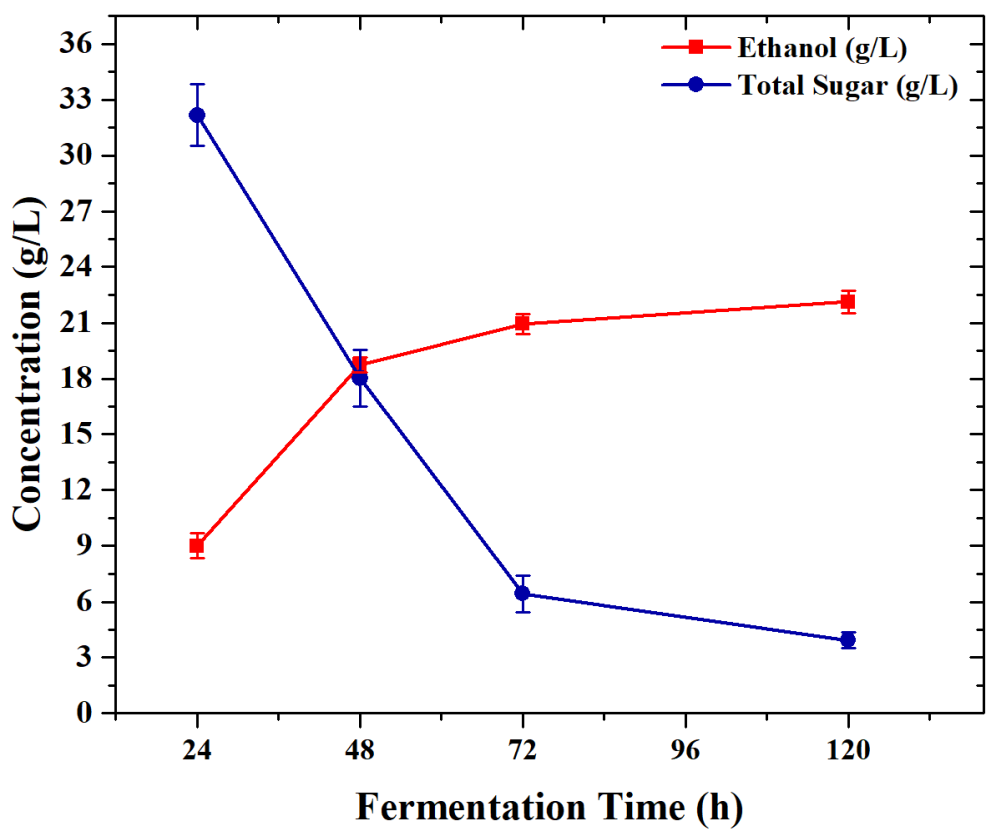

Figure 3. Effect of fermentation time on bioethanol yield and substrate consumption for EFYB hydrolysate

High bioethanol yield and productivity shows that the EFYB hydrolysate was effectively converted into bioethanol and was free from any fermentation inhibitor. These fermentation parameter obtained in the present study is comparable with the values reported in the literature ${ }^{34-38}$.

\subsection{Estimation of kinetic parameters}

The kinetic parameters of bioethanol production from EFYB by S. cerevisiae were estimated by fitting the experimental data to modified Gompertz model. This model represents the relationship between ethanol produced and fermentation time between experimental finding and model calculated value (Figure 4). 
The experimental data of bioethanol fermentation was fitted to the proposed model equation using Microsoft Excel 2010 solver by non-linear regression using least square technique. The calculated correlation coefficient was above 0.99 suggesting the accuracy of the model. The fitness of the generated kinetic model was predicted by calculating the mean square error (MSE) and variance. The lesser value $\left(9.85 \times 10^{-5}\right)$ of MSE and variance $\left(\square \square \square \square \square \square \times 10^{-8}\right)$ for bioethanol production thus supports the efficiency of the kinetic model generated.

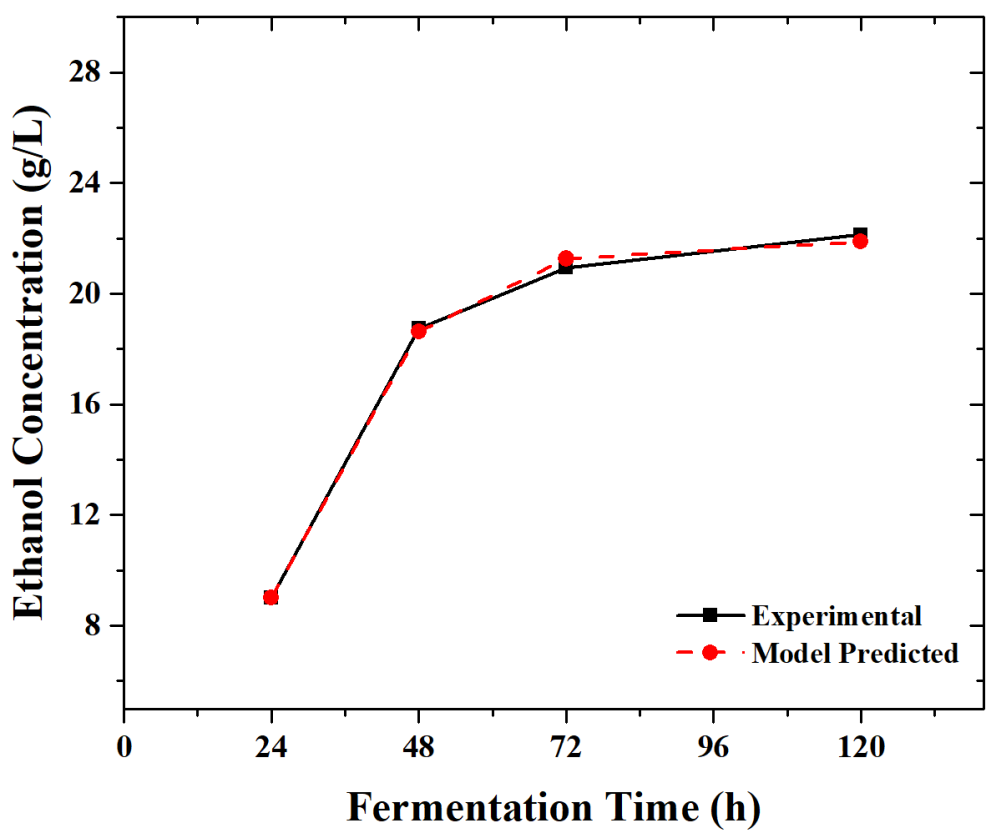

Figure 4. Fitting the modified Gompertz model to experimental data

The kinetic parameters of the modified Gompertz model are calculated to be maximum ethanol concentration $\left(\mathrm{P}_{\mathrm{m}}\right)=21.90 \mathrm{~g} / \mathrm{L}$, maximum ethanol production rate $\left(\mathrm{r}_{\mathrm{pm}}\right)=0.57 \mathrm{~g} / \mathrm{L} \cdot \mathrm{h}$ and lag phase $\left(t_{\mathrm{L}}\right)=8.22 \mathrm{~h}$. The predicted value of productivity in the present research output was observed to be in good agreement with experimental value.

\section{Conclusion}

The process developed in this study was more economic due to involvement of minimal unit operation and rapid saccharification process in order to release fermentable sugar to produce bioethanol. The present study investigated the potentiality of Elephant foot yam (A. 
paeoniifolius) biomass as a successful feedstock for bioethanol production. The feedstock under investigation was hydrolysed prior to fermentation by the action of $\mathrm{HCl}$ acid followed with pressure cooking. The process parameter affecting the hydrolysate concentration was studied by varying one factor at a time and statistically optimized using CCD. The resultant optimum $45.87 \mathrm{~g} / \mathrm{L}$ of total sugar at $1.32 \% \mathrm{v} / \mathrm{v}$ of $\mathrm{HCl}, 5.83 \% \mathrm{w} / \mathrm{v}$ of $\mathrm{EFYB}$ and $66.84 \mathrm{~min}$ of pressure cooking time was obtained. A second order polynomial equation was generated and validated to describe the saccharification of A. paeoniifolius. The fermentation of EFYB hydrolysate using S.cerevisiae in STBR enhanced the yield and productivity of bioethanol to $0.51 \mathrm{~g} / \mathrm{g}$ and $0.30 \mathrm{~g} / \mathrm{L} . \mathrm{h}$ respectively. Gompertz model was accurately fit into bioethanol fermentation process and kinetic parameters were determined by using nonlinear regression with the least square method.

\section{Materials and Methods}

\subsection{Raw material}

Elephant foot yam (EFY) was collected from the coastal district of Karnataka, India $\left(12^{\circ} 52^{\prime} 01.5^{\prime \prime} \mathrm{N} 74^{\circ} 50^{\prime} 21.6 " \mathrm{E}\right)$. Fully grown, 7-8 month old yam was harvested for this study. The EFY was cleaned with fresh water to remove soil and other unwanted debris. The whole yam, except the dark brown outer skin was used as a substrate for pretreatment and bioethanol production. The EFY tubers were chopped into smaller pieces and sun dried for 3 days to remove excess moisture. The chopped tubers were further dried in hot air oven at $60^{\circ} \mathrm{C}$ for $12 \mathrm{~h}$. The bone dry samples were milled to flour and stored in an air tight container for further use.

\subsection{Compositional analysis of Elephant Foot Yam Biomass (EFYB)}

The chemical compositions of EFYB such as carbohydrate, starch, protein and ash content were determined experimentally by adapting AOAC standard protocols ${ }^{39}$. The compositional 
analysis was carried out by taking $1 \mathrm{~g}$ of EFYB. The total sugar in the biomass was estimated by using spectrophotometric technique as per Dubois method ${ }^{40}$.

\subsection{Pretreatment Process}

The powdered EFYB was subjected to treatment with dilute acid followed by pressure cooking to hydrolyse the carbohydrate to fermentable sugar. The process was carried out by taking $100 \mathrm{~mL}$ of acid in $250 \mathrm{~mL}$ screw capped bottle to avoid any evaporation loss during pressure cooking. After the pretreatment process the hydrolysate were separated by filtering it through ceramic mesh filter and the amount of total sugar was quantified.

\subsubsection{Acid pretreatment}

The pretreatment of biomass with dilute mineral acid is proven to be one of the effective methods of pretreatment in industrial scale ${ }^{41}$. Several studies have been reported by utilizing mineral and organic acids in the pretreatment process to obtain C6 and C5 sugars ${ }^{42}$. The dilute acid pretreatment significantly reduces the reaction activation energy, thereby improving the cellulose hydrolysis rate ${ }^{24}$. The acid pretreatment of EFYB was carried out by mixing the biomass with $100 \mathrm{~mL}$ of dilute hydrochloric acid $(\mathrm{HCl})$. In order to study the correlation among the acid concentration and biomass handling capacity, the acid strength was varied between $1 \square 9 \%$ v/v by keeping EFYB load constant at 5\%w/v. Further, EFYB load was varied between $1 \square \square \square \% \mathrm{w} / \mathrm{v}$ by treating it constantly with $\mathrm{HCl}$ concentration at 3\%v/v.

\subsubsection{Physicochemical pretreatment}

The physicochemical pretreatment is a cost effective and efficient technique with lower energy consumption. In this process steam penetrates into the biomass and expands cell wall which facilitates acid to hydrolyse the carbohydrates ${ }^{42}$. The acid treated EFYB was pressure cooked in $12 \mathrm{~L}$ domestic cooker in $250 \mathrm{~mL}$ screw capped bottle. The contents were pressure cooked at $121^{\circ} \mathrm{C}$ at 15 psi by varying the residence time between $20 \square 80 \mathrm{~min}$. The volume of water inside 
the pressure cooker was maintained constant to avoid variation in preheating time. After the pressure cooking the content were cooled to ambient temperature and filtered. The total sugar released after the hydrolysis was determined.

\subsection{Optimization of pretreatment parameter using central composite design (CCD)}

The pretreatment process parameter such as acid concentration, EFYB load and pressure cooking time significantly affecting the degree of hydrolysis were optimized using response surface methodology (RSM). In RSM the effect of pretreatment factors on the release of total sugar was represented by second order polynomial equation as shown in Equation $1^{43-45}$.

Total suagr $=a_{0}+\sum_{i=1}^{3} a_{i} x_{i}+\sum_{i<j}^{k} a_{i j} x_{i} x_{j}+\sum_{i=1}^{3} a_{i i} x_{i}^{2}$ Equation 2

Where, $\mathrm{a}$ is the regression coefficient and $\mathrm{x}$ is the independent factors

The experiments were designed and analysed using statistical software MINITAB 17 trial version. A central composite design with three pretreatment factors taken was taken in 5 coded levels ( $-\alpha, \square 1,0,+1$ and $+\alpha$ ) consisting of 20 experimental combinations which were taken in this study. $\pm \alpha$ corresponds to the star or axial point having value \pm 1.68 and other coded values $(\square 1,0$, and +1$)$ represent the low, mid and high range value respectively.

The factors such as acid concentration (A), EFYB load (B) and pressure cooking time (C) were taken as independent variable and total sugar released during the hydrolysis was taken as response or dependent variable. The CCD levels were taken by conducting pretreatment experiment in which one factor was varied by retaining other factors at fixed value. In design, the mid-value (0) was selected by increasing the range of factors until maximum response (total sugar) was obtained. The experimental combination for CCD and response is tabulated in Table 2. The measurement of total sugar was taken in triplicate to minimize the measurement error. 
Table 2. CCD design for the optimization of physicochemical pretreatment parameters of EFYB for the release of total sugar $(\mathrm{g} / \mathrm{L})$

\begin{tabular}{|c|c|c|c|c|}
\hline HCl & EFYB & Time & \multicolumn{2}{|c|}{ Total Sugar $(\mathbf{g} / \mathbf{L})$} \\
\cline { 4 - 5 }$(\boldsymbol{\%} \mathbf{v} / \mathbf{v})$ & $(\boldsymbol{\%} \mathbf{w} / \mathbf{v})$ & $(\mathbf{m i n})$ & Experiment & Predicted \\
\hline 2 & 4 & 20 & 20.87 & 23.08 \\
\hline 4 & 4 & 20 & 20.84 & 21.25 \\
\hline 2 & 8 & 20 & 26.87 & 22.40 \\
\hline 4 & 8 & 20 & 21.62 & 20.58 \\
\hline 2 & 4 & 60 & 35.27 & 40.56 \\
\hline 4 & 4 & 60 & 40.83 & 38.74 \\
\hline 2 & 8 & 60 & 47.92 & 39.89 \\
\hline 4 & 8 & 60 & 36.01 & 38.07 \\
\hline 1.32 & 6 & 40 & 36.13 & 38.42 \\
\hline 4.68 & 6 & 40 & 35.67 & 35.36 \\
\hline 3 & 2.64 & 40 & 33.8 & 29.65 \\
\hline 3 & 9.36 & 40 & 22.39 & 28.52 \\
\hline 3 & 6 & 6.36 & 10.9 & 11.93 \\
\hline 3 & 6 & 73.64 & 40.39 & 41.34 \\
\hline 3 & 6 & 40 & 36.26 & 35.73 \\
\hline 3 & 6 & 40 & 32.51 & 35.73 \\
\hline 3 & 6 & 40 & 38.9 & 35.73 \\
\hline 3 & 6 & 40 & 33.19 & 35.73 \\
\hline 3 & 6 & 40 & 35.97 & 35.73 \\
\hline 3 & 6 & 40 & 37.92 & 35.73 \\
\hline
\end{tabular}

\subsection{Culture and media preparation}

Saccharomyces cerevisiae MTCC 170 was procured from Microbial Type culture collection and gene bank (MTCC), Pune, India. The lyophilized culture was revived in 100mL media composition of $2 \mathrm{~g}$ glucose, $2 \mathrm{~g}$ peptone and $1 \mathrm{~g}$ yeast extract. After the reactivation, culture was subjected to gram staining to check for any possible contamination.

\subsection{Bioethanol fermentation in Stirred tank batch reactor (STBR)}

The bioethanol fermentation was carried out using laboratory stirred tank batch reactor (STBR) (Figure 5) with capacity of 1L manufactured by Borg Scientific, Tamil Nadu, India. The glass reactor was fed with $700 \mathrm{~mL}$ of production media, which consists of EFYB hydrolysate pretreated under optimal pretreatment condition. The media was autoclaved at $121^{\circ} \mathrm{C}$ for $20 \mathrm{~min}$ 
and $\mathrm{pH}$ was adjusted to 6.9-7 using $\mathrm{pH}$ controller. The reactor and contents was cooled to room temperature by circulating chilled water through cooling coil. Sterile silicon tubes were connected to inlet port, sampling port and inoculation port. The aerobic condition was maintained by sparging $2 \mathrm{~mL} / \mathrm{min}$ sterile air through nozzle sparger. The vent was connected with sterile $0.2 \square \mathrm{m}$ air filter.

S. cerevisiae cultured in activation media and $6 \mathrm{~h} \log$ phase culture was taken for inoculation. $5 \% \mathrm{v} / \mathrm{v}$ of $\log$ phase culture was transferred to the reactor aseptically through the inoculation port using peristaltic pump. Contents inside were kept under suspension using turbine impeller of variable speed, during the operation of the reactor. Cell maintenance under suspension was set at 50rpm to prevent any cell death due to nutrient depletion and also to avoid cell disruption due to rotation of agitator blade.

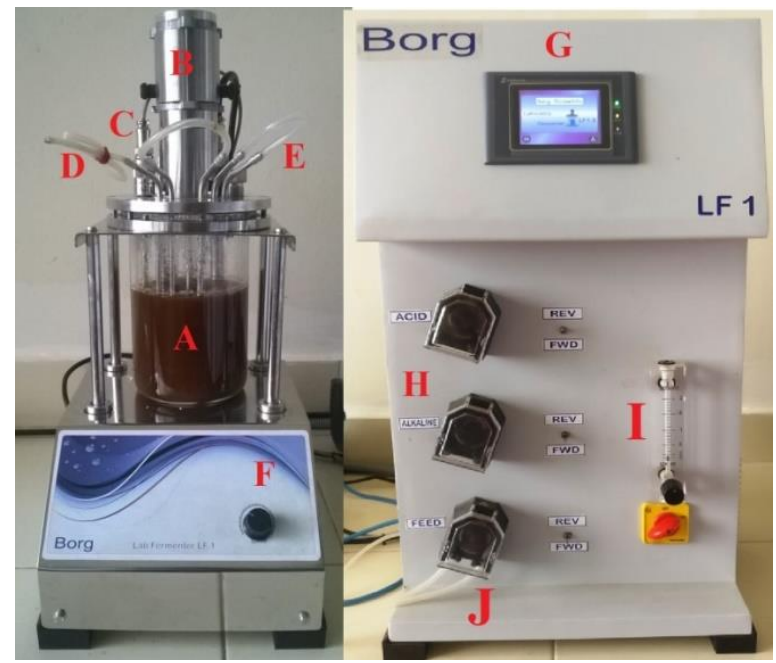

Figure 5. Lab scale Stirred tank batch reactor (STBR) A) Glass reactor wall B) Agitator motor C) Temperature probe D) Feed Inlet port E) Sampling Port F) rpm regulator G) Control panel H) acid/alkali metring pump I) Air regulator J) Feed/Inoculation pump

Sampling was carried out at $24 \mathrm{~h}$ interval and sampling port was regularly sterilized using IPA to avoid any contamination. These samples were analysed using Gas Chromatography (GC) for ethanol estimation and bioethanol concentration was measured in Gas Chromatography. The reduction in total sugar and ethanol yield was also accounted. 


\subsection{Analysis}

The analysis of ethanol samples were done in Gas Chromatography (GC) (Shimadzu Corporation, Tokyo, Japan) equipped with a flame ionization detector (FID) and ZB-Wax capillary column $(30 \mathrm{~m} \times 0.25 \mathrm{~mm} \times 0.25 \mu \mathrm{m})$ using high purity $\mathrm{N}_{2} \quad(99.99 \%)$ as the carrier gas. The temperature of the injector and detector was maintained at $180^{\circ} \mathrm{C}$ and $200^{\circ} \mathrm{C}$ respectively. The column temperature was increased at controlled rate by holding initial temperature at $40^{\circ} \mathrm{C}$ for $1 \mathrm{~min}$. Further column temperature was increased at a ramp rate of $10^{\circ} \mathrm{C} / \mathrm{min}$ to $80^{\circ} \mathrm{C}$ and hold for $1 \mathrm{~min}$. The column temperature was raised at $25^{\circ} \mathrm{C} / \mathrm{min}$ to $150^{\circ} \mathrm{C}$ and hold for $1 \mathrm{~min}$. The analysis was carried out by taking $0.2 \square \mathrm{L}$ of fermentation sample.

\subsection{Prediction of kinetic model}

Kinetic model of any fermentation process describe the formation of fermentation product with respect to time. Thus, kinetic model generated for a process modulates in designing the process control, reducing the operational cost and enhancing the product quality and yield respectively ${ }^{46}$. In the present investigation, bioethanol production was modelled by modified Gompertz model (Equation 2). This model predicts the kinetic terms of bioethanol fermentation such as maximum rate of productivity, maximum bioethanol concentration and production lag time. These kinetic values can be used to scale up the bioethanol fermentation process ${ }^{47,48}$.

$\left.P=P_{m} e^{\left\{-e^{\left[\frac{r_{p m} e^{1}}{P_{m}}\right]\left(t_{L}-t\right)+1}\right.}\right\}$ Equation 3

Where, $P$ is the ethanol concentration $(\mathrm{g} / \mathrm{L}), \mathrm{P}_{\mathrm{m}}$ is the maximum ethanol concentration $(\mathrm{g} / \mathrm{L})$, $\mathrm{r}_{\mathrm{pm}}$ is the maximum productivity of bioethanol, $\mathrm{t}_{\mathrm{L}}$ and $\mathrm{t}$ are the time of lag phase and fermentation time respectively. The bioethanol yield over the total sugar consumption and \% sugar utilization was calculated as per the Equation 3 and Equation 4 shown below ${ }^{48}$. 


$$
Y_{P / s}=\frac{P_{f}-P_{0}}{S_{0}-S_{f}}
$$

$\%$ sugar consumption $=\left(1-\frac{s_{f}}{s_{0}}\right) \times 100$ Equation 5

Where, $\mathrm{Y} / \mathrm{s}$ is the bioethanol yield, $\mathrm{P}_{\mathrm{f}}$ and $\mathrm{P}_{0}$ are the final and initial bioethanol concentration $(\mathrm{g} / \mathrm{L}), \mathrm{S}_{\mathrm{f}}$ and $\mathrm{S}_{0}$ are the final and initial sugar concentration $(\mathrm{g} / \mathrm{L})$.

\section{Author Contributions}

P. Ujwal, K. Sandesh and V.B. Shet designed the research; S.P. Rakshitha, K. V. Keerthana, P. Anjuna, S.G. Sangam and J.N. Neetha performed experimental work; K. Sandesh did data analysis, Visualization and Validation; Operation of bioreactor was carried out by P. Ujwal, K. Sandesh and V.B. Shet; N. M. Mubarak served as the scientific co-ordinator; P. Ujwal, K. Sandesh and V.B. Shet wrote the manuscript.

\section{Additional Information}

The authors declare that they have no conflicts of interest regarding the publication of this paper.

\section{Acknowledgement}

The authors are grateful to the Principal, NMAMIT, Nitte for supporting with the department facilities. Thanks are due to Karnataka State Council for Science and Technology (KSCST), under Biofuel category for the necessary support.

\section{Reference}

1. Lin, Y. \& Tanaka, S. Ethanol fermentation from biomass resources: Current state and prospects. Applied Microbiology and Biotechnology vol. 69 627-642 (2006).

2. Khan, I. \& Akhtar, M. W. Bioenergy Production From Plant Biomass: Bioethanol From Concept To Reality. Nat. Preced. (2011) doi:10.1038/npre.2011.6286.1. 
3. Zaky, A. S., Greetham, D., Tucker, G. A. \& Du, C. The establishment of a marine focused biorefinery for bioethanol production using seawater and a novel marine yeast strain. Sci. Rep. 8, 1-14 (2018).

4. Mikulski, D. \& Kłosowski, G. Microwave-assisted dilute acid pretreatment in bioethanol production from wheat and rye stillages. Biomass and Bioenergy 136, 105528 (2020).

5. Sayaslan, A. et al. Use of durum wheat clear flour in vital gluten and bioethanol production. J. Cereal Sci. 80, 50-56 (2018).

6. Luiza Astolfi, A. et al. Simultaneous saccharification and fermentation of Spirulina sp. and corn starch for the production of bioethanol and obtaining biopeptides with high antioxidant activity. Bioresour. Technol. 301, 122698 (2020).

7. Szambelan, K., Nowak, J., Szwengiel, A., Jeleń, H. \& Lukaszewski, G. Separate hydrolysis and fermentation and simultaneous saccharification and fermentation methods in bioethanol production and formation of volatile by-products from selected corn cultivars. Ind. Crops Prod. 118, 355-361 (2018).

8. Liao, B., Hill, G. A. \& Roesler, W. J. Stable expression of barley $\alpha$-amylase in S. cerevisiae for conversion of starch into bioethanol. Biochem. Eng. J. 64, 8-16 (2012).

9. Wang, X., Tian, S., Lou, H. \& Zhao, R. A reliable method for predicting bioethanol yield of different varieties of sweet potato by dry matter content. Grain Oil Sci. Technol. (2020) doi:10.1016/j.gaost.2020.06.002.

10. Weber, C. T., Trierweiler, L. F. \& Trierweiler, J. O. Food waste biorefinery advocating circular economy: Bioethanol and distilled beverage from sweet potato. J. Clean. Prod. 268, 121788 (2020).

11. Chuck-Hernandez, C., Perez-Carrillo, E. \& Serna-Saldivar, S. O. Production of bioethanol from steam-flaked sorghum and maize. J. Cereal Sci. 50, 131-137 (2009).

12. Prasad, S. et al. Screening and evaluation of cellulytic fungal strains for saccharification and bioethanol production from rice residue. Energy 190, 116422 (2020).

13. Juodeikiene, G. et al. Combined fermentation for increasing efficiency of bioethanol production from Fusarium sp. contaminated barley biomass. in Catalysis Today vol. 223 108-114 (Elsevier, 2014).

14. Lyu, H., Zhang, J., Zhai, Z., Feng, Y. \& Geng, Z. Life cycle assessment for bioethanol production from whole plant cassava by integrated process. J. Clean. Prod. 269, 121902 (2020).

15. Melikoglu, M. \& Turkmen, B. Food waste to energy: Forecasting Turkey's bioethanol generation potential from wasted crops and cereals till 2030. Sustain. Energy Technol. Assessments 36, 100553 (2019).

16. Mohr, A. \& Raman, S. Lessons from first generation biofuels and implications for the sustainability appraisal of second generation biofuels. Effic. Sustain. Biofuel Prod. Environ. Land-Use Res. 63, 281-310 (2015).

17. Vendruscolo, F. Starch: a potential substrate for biohydrogen production. Int. J. Energy 
Res. 39, 293-302 (2015).

18. Michael Sauer, M. S., Mattanovich, D. \& Marx, H. Renewable Resources To Commodity Bioprocessing of Renewable Resources To Commodity Bioproducts. (Wiley, 2014).

19. Lu, C., Zhao, J., Yang, S. T. \& Wei, D. Fed-batch fermentation for n-butanol production from cassava bagasse hydrolysate in a fibrous bed bioreactor with continuous gas stripping. Bioresour. Technol. 104, 380-387 (2012).

20. Phukoetphim, N., Salakkam, A., Laopaiboon, P. \& Laopaiboon, L. Kinetic models for batch ethanol production from sweet sorghum juice under normal and high gravity fermentations: Logistic and modified Gompertz models. J. Biotechnol. 69-75 (2017) doi:10.1016/j.jbiotec.2016.12.012.

21. Nikolić, S., Mojović, L., Rakin, M., Pejin, D. \& Nedović, V. Effect of different fermentation parameters on bioethanol production from corn meal hydrolyzates by free and immobilized cells of Saccharomyces cerevisiae var. ellipsoideus. J. Chem. Technol. Biotechnol. 84, 497-503 (2009).

22. Mohd Azhar, S. H. et al. Yeasts in sustainable bioethanol production: A review. Biochemistry and Biophysics Reports vol. 10 52-61 (2017).

23. Zhang, J., Shao, S. \& Bao, J. Long term storage of dilute acid pretreated corn stover feedstock and ethanol fermentability evaluation. Bioresour. Technol. 201, 355-359 (2016).

24. Rabemanolontsoa, H. \& Saka, S. Various pretreatments of lignocellulosics. Bioresour. Technol. 199, 83-91 (2016).

25. Neves, P. V., Pitarelo, A. P. \& Ramos, L. P. Production of cellulosic ethanol from sugarcane bagasse by steam explosion: Effect of extractives content, acid catalysis and different fermentation technologies. Bioresour. Technol. 208, 184-194 (2016).

26. El-Mekkawi, S. A., Abdo, S. M., Samhan, F. A. \& Ali, G. H. Optimization of some fermentation conditions for bioethanol production from microalgae using response surface method. Bull. Natl. Res. Cent. 43, 1-8 (2019).

27. Raja, S. \& Murty, V. R. Optimization of Aqueous Two-Phase Systems for the Recovery of Soluble Proteins from Tannery Wastewater Using Response Surface Methodology. $J$. Eng. (United States) 2013, 1-10 (2013).

28. Chattopadhyay, A., Saha, B., Pal, S., Bhattacharya, A. \& Sen, H. Quantitative and qualitative aspects of elephant foot Yam. Int. J. Veg. Sci. 16, 73-84 (2010).

29. Suriya, M., Baranwal, G., Bashir, M., Reddy, C. K. \& Haripriya, S. Influence of blanching and drying methods on molecular structure and functional properties of elephant foot yam (Amorphophallus paeoniifolius) flour. LWT - Food Sci. Technol. 68, 235-243 (2016).

30. Behera, S. S., Panda, S. H., Panda, S. K. \& Kumar, A. Biochemical analysis of elephant foot yam (Amorphophallus paeoniifolius) lacto-pickle with probiotic Lactobacillus plantarum. Ann. Microbiol. 69, 577-590 (2019).

31. Singh, S., Khanna, S., Moholkar, V. S. \& Goyal, A. Screening and optimization of 
pretreatments for Parthenium hysterophorus as feedstock for alcoholic biofuels. Appl. Energy 129, 195-206 (2014).

32. Chaturvedi, V. \& Verma, P. An overview of key pretreatment processes employed for bioconversion of lignocellulosic biomass into biofuels and value added products. 3 Biotech 3, 415-431 (2013).

33. Shet, V. B. et al. Comparison of response surface methodology and artificial neural network to enhance the release of reducing sugars from non-edible seed cake by autoclave assisted $\mathrm{HCl}$ hydrolysis. 3 Biotech 8, 1-8 (2018).

34. Yeh, R. H., Lin, Y. S., Wang, T. H., Kuan, W. C. \& Lee, W. C. Bioethanol production from pretreated Miscanthus floridulus biomass by simultaneous saccharification and fermentation. Biomass and Bioenergy 94, 110-116 (2016).

35. Zhao, J. \& Xia, L. Bioconversion of corn stover hydrolysate to ethanol by a recombinant yeast strain. Fuel Process. Technol. 91, 1807-1811 (2010).

36. Kumari, R. \& Pramanik, K. Bioethanol production from Ipomoea Carnea biomass using a potential hybrid yeast strain. Appl. Biochem. Biotechnol. 171, 771-785 (2013).

37. Sathesh-Prabu, C. \& Murugesan, A. G. Potential utilization of sorghum field waste for fuel ethanol production employing Pachysolen tannophilus and Saccharomyces cerevisiae. Bioresour. Technol. 102, 2788-2792 (2011).

38. Shet, V. B. et al. Acid hydrolysis optimization of cocoa pod shell using response surface methodology approach toward ethanol production. Agric. Nat. Resour. 52, 581-587 (2018).

39. Becker, J. Plasmons as Sensors. Association of Analytical Communities vol. 1 141-144 (2012).

40. Dubois, G. Smith (1956) M. Dubois, KA Gilles, JK Hamilton, PA Rebers and F. Smith, Colorimetric method for determination of sugars and related substances. Anal. Chem. 28, 350-356 (1956).

41. Taherzadeh, M. J. \& Karimi, K. Pretreatment of lignocellulosic wastes to improve ethanol and biogas production: A review. Int. J. Mol. Sci. 9, 1621-1651 (2008).

42. Kumar, P., Barrett, D. M., Delwiche, M. J. \& Stroeve, P. Methods for pretreatment of lignocellulosic biomass for efficient hydrolysis and biofuel production. Ind. Eng. Chem. Res. 48, 3713-3729 (2009).

43. Sandesh, K., Amin, S., Kiran, H. T. \& Vaman Rao, C. Optimization of Pretreatment of Saccharum spontaneum (Kans Grass) Biomass for Production of Alcoholic Biofuels. Res. J. Pharm. Biol. Chem. Sci. Optim. 8, 117-126 (2017).

44. Sandesh, K., Shishir, R. K. \& Vaman Rao, C. Optimization and comparison of induction heating and LPG assisted acid pretreatment of cocoa pod for ABE fermentation. Fuel 262, 116499 (2020).

45. Tripathi, M., Bhatnagar, A., Mubarak, N. M., Sahu, J. N. \& Ganesan, P. RSM optimization of microwave pyrolysis parameters to produce OPS char with high yield and large BET surface area. Fuel 277, 118184 (2020). 
46. Dodić, J. M. et al. Kinetic modelling of batch ethanol production from sugar beet raw juice. Appl. Energy 99, 192-197 (2012).

47. Fan, S. et al. Kinetic model of continuous ethanol fermentation in closed-circulating process with pervaporation membrane bioreactor by Saccharomyces cerevisiae. Bioresour. Technol. 177, 169-175 (2015).

48. Srimachai, T., Nuithitikul, K., O-Thong, S., Kongjan, P. \& Panpong, K. Optimization and Kinetic Modeling of Ethanol Production from Oil Palm Frond Juice in Batch Fermentation. Energy Procedia vol. 79 (Elsevier B.V., 2015). 
Figures
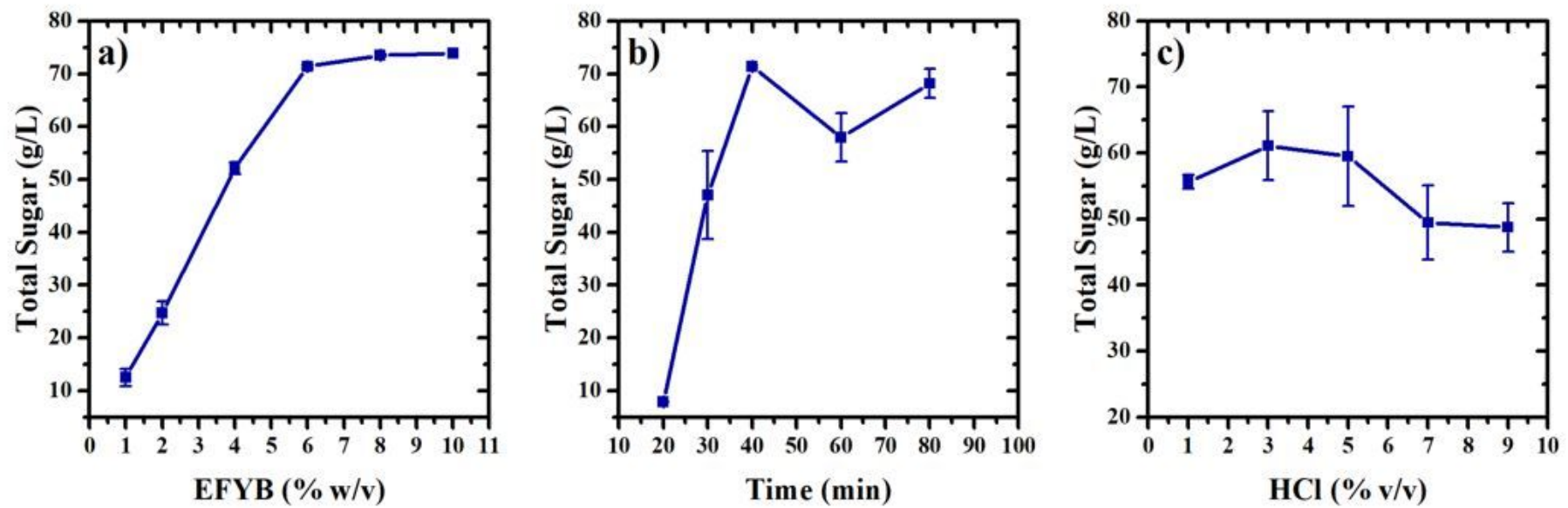

Figure 1

Effect of pretreatment parameter on fermentable sugar (a) \%EFYB (b) Pressure cooking time (c) \% $\mathrm{HCl}$ on total sugar release $(\mathrm{g} / \mathrm{L})$
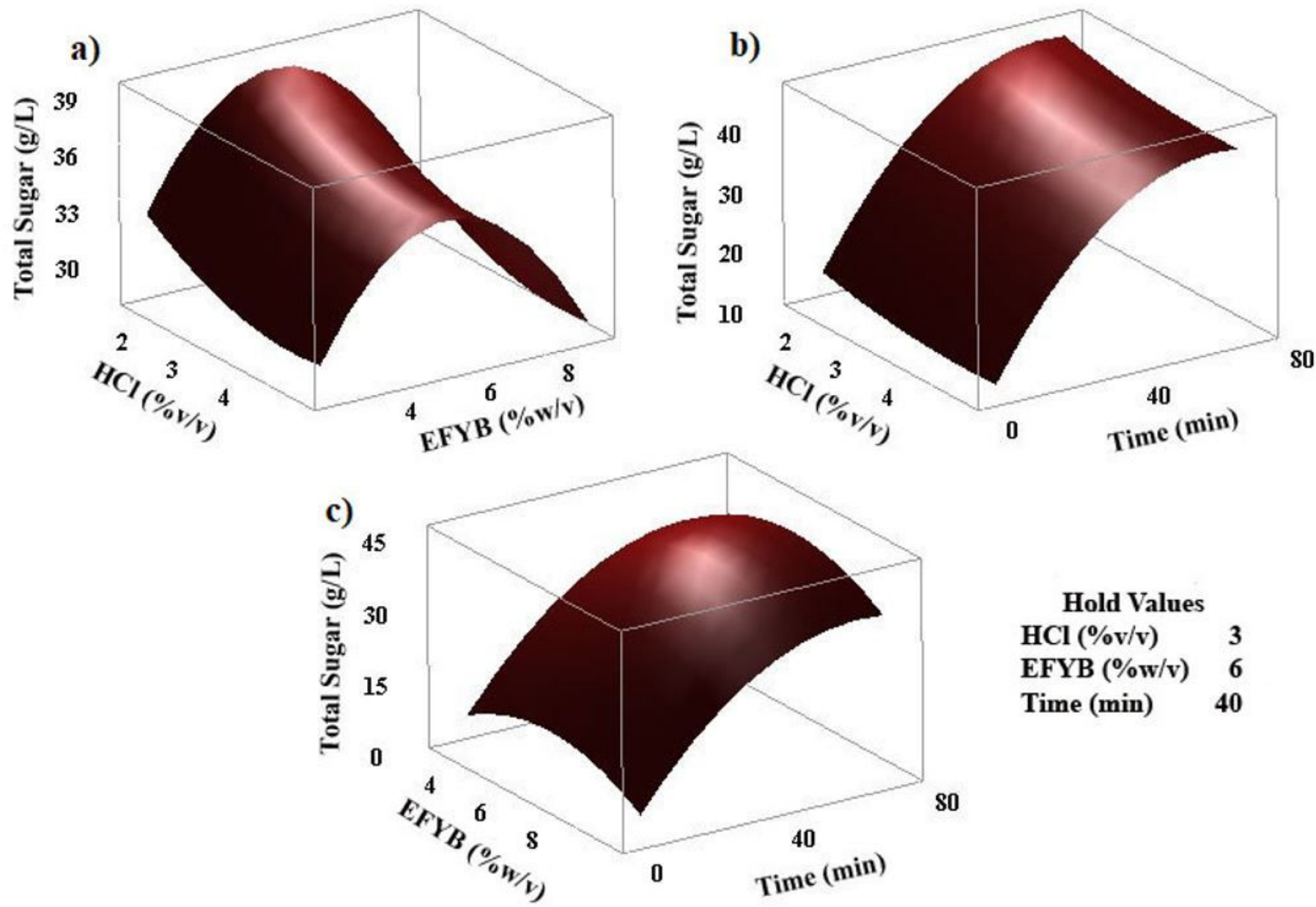

Hold Values $\mathrm{HCl}(\% \mathrm{v} / \mathrm{v}) \quad 3$

EFYB (\%w/v) 6

Time (min) $\quad 40$

Figure 2 
(a-c). 3-D surface plot for the pretreatment of EFYB for bioethanol production.

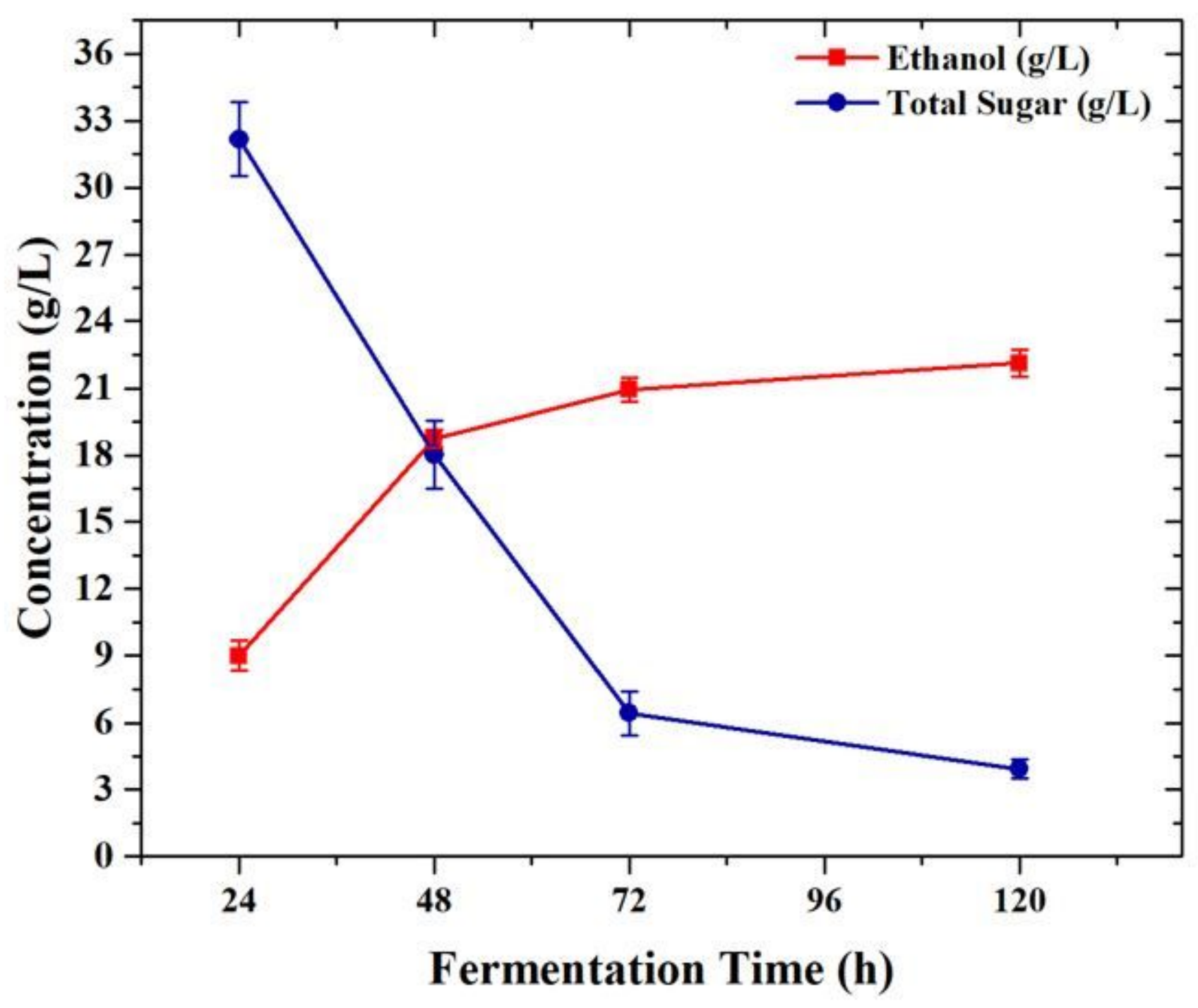

Figure 3

Effect of fermentation time on bioethanol yield and substrate consumption for EFYB hydrolysate 


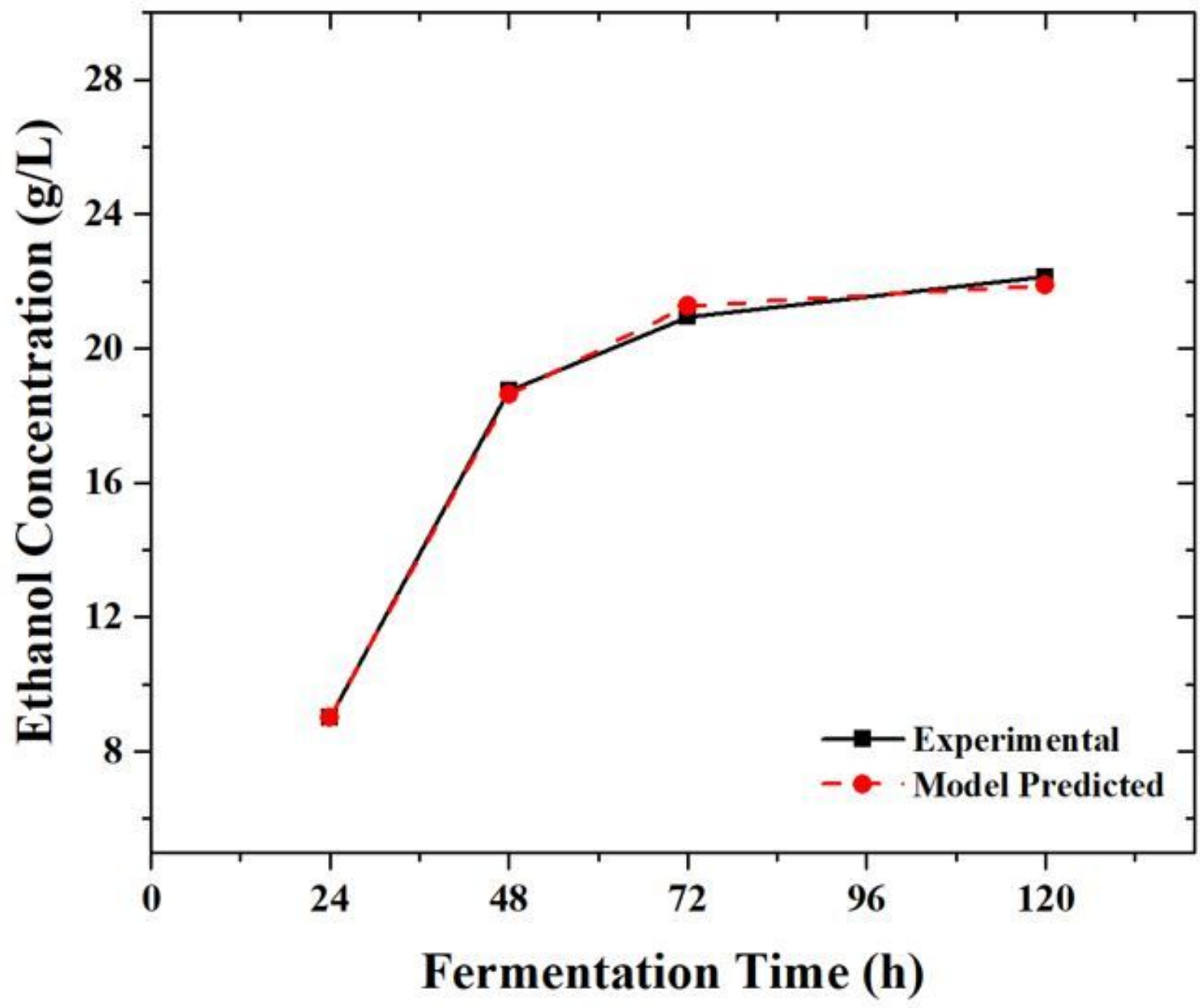

Figure 4

Fitting the modified Gompertz model to experimental data 


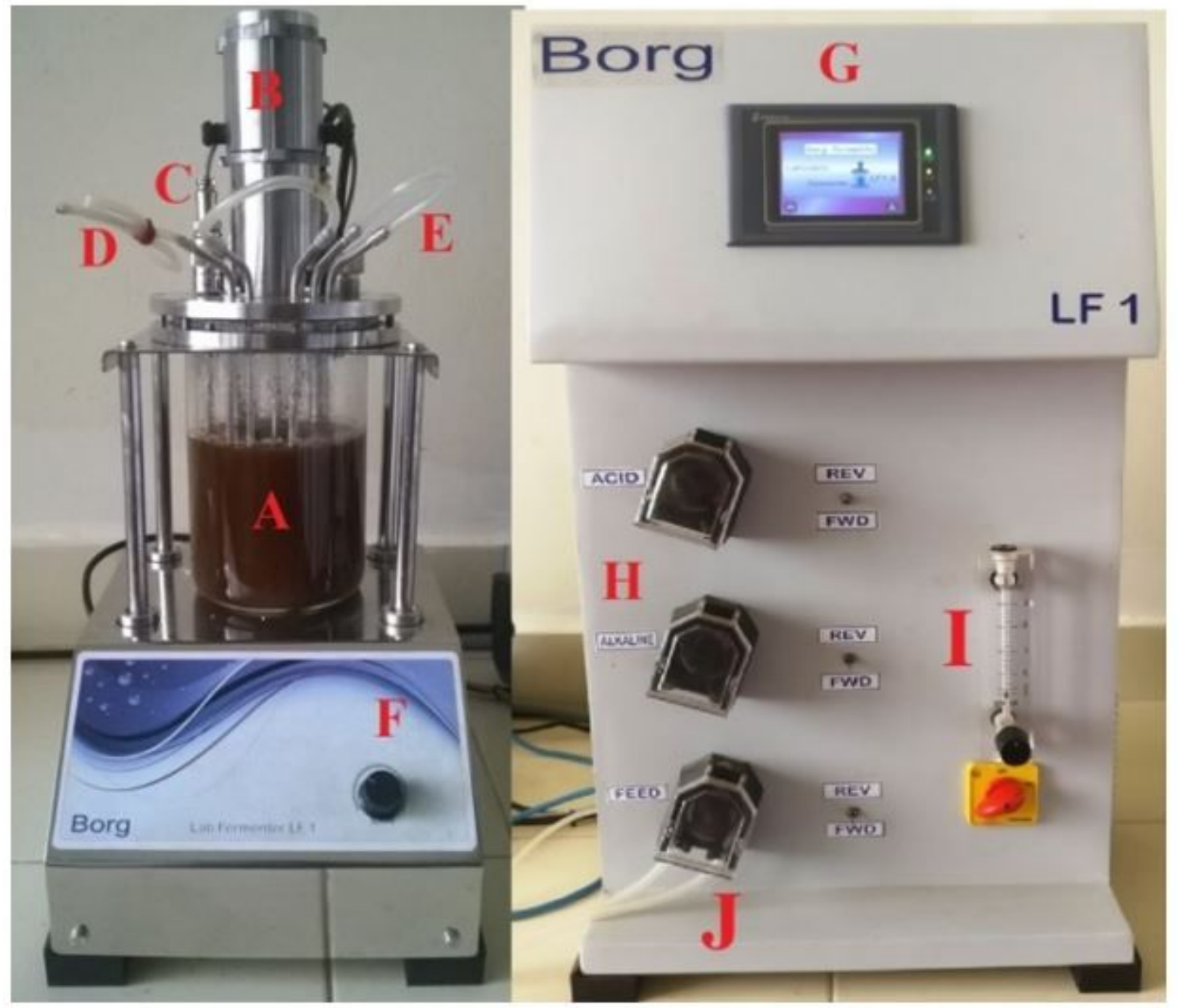

\section{Figure 5}

Lab scale Stirred tank batch reactor (STBR) A) Glass reactor wall B) Agitator motor C) Temperature probe D) Feed Inlet port E) Sampling Port F) rpm regulator G) Control panel H) acid/alkali metring pump I) Air regulator J) Feed/Inoculation pump 